Pesq. Vet. Bras. 30(7):551-553, julho 2010

\title{
IgM e IgG como marcadores da infecção transplacentária por Neospora caninum em fetos bovinos ${ }^{1}$
}

\begin{abstract}
Gustavo C. Cadore ${ }^{2}$, Fernanda S.F. Vogel ${ }^{3^{*}}$, Luis Antonio Sangioni ${ }^{3}$, Hilda F.J. Pena $^{4}$ e Solange M. Gennari ${ }^{4}$

ABSTRACT.- Cadore G.C., Vogel F.S.F., Sangioni L.A., Pena H.F.J. \& Gennari S.M. 2010. [IgM and IgG as markers of infection transplacentary Neospora caninum in bovine fetuses.] IgM e IgG como marcadores da infecção transplacentária por Neospora caninum em fetos bovinos. Pesquisa Veterinária Brasileira 30(7):551-553. Setor de Medicina Veterinária Preventiva (Doenças Parasitárias), Universidade Federal de Santa Maria, Camobi, Santa Maria, RS 97105-900, Brazil. E-mail: fervogel@smail.com

The aim of this study was to determine the occurrence of anti-Neospora caninum antibodies in serum samples collected from 260 bovine fetuses, between July 2007 and March 2008, in an abattoir in the municipality of Santa Maria, Rio Grande do Sul, Brazil. An indirect fluorescent antibody test was used to detect anti- $N$. caninum immunoglobulins $\mathrm{G}(\operatorname{lgG})$ and $\mathrm{M}(\operatorname{lgM})$, using a cut-off of 1:25. Considering IgG or IgM detection, 15\% (39/260) of the samples tested were found positive. Among the positive samples, 38 (97.4\%) were positive for IgG and $6(15.4 \%)$ for $\operatorname{lgM}$. However $5(12.8 \%)$ of it were positive for both $\operatorname{lgG}$ and $\operatorname{lgM}$. These results are in agreement with the proven ability of $N$. caninum to fetal infection. IgM testing was few relevant to detect $N$. caninum transplacental infection through fetal bovine serum analisys.
\end{abstract}

INDEX TERMS: Neospora caninum, indirect fluorescent antibody test, bovine fetuses, immunoglobulin $\mathrm{G}$ and $\mathrm{M}$ (IgG and $\operatorname{lgM})$.

RESUMO.- O objetivo deste estudo foi determinar a ocorrência de anticorpos anti-Neospora caninum em 260 amostras de soro coletadas de fetos bovinos de julho de 2007 a março de 2008, em abatedouro do município de Santa Maria, Rio Grande do Sul, Brasil. Para detecção de anticorpos anti- $N$. caninum, a técnica de imunofluorescência indireta foi utilizada tanto para a detecção de imunoglobulinas $\mathrm{G} e$ M. Amostras com títulos e" 25 foram consideradas positivas. Das 260 amostras testadas, 15\% (39/260) foram positivas para anticorpos anti- N. caninum. Destas, em $38(97,4 \%)$ foi detectada a presença de IgG anti- $N$. caninum e em seis $(15,4 \%)$ de IgM. Em cinco amostras (12,8\%) detectaram-se ambos, IgG e lgM. Os resultados reafirmam a habilidade do N. caninum em determinar infecção fetal. A pesquisa de

\footnotetext{
${ }^{1}$ Recebido em 2 de outubro de 2009.

Aceito para publicação em 13 de janeiro de 2010

2 Curso de Pós-Graduação em Medicina Veterinária, Universidade Federal de Santa Maria (UFSM), Rua Roraima 1000, Camobi, Santa Maria, RS 97105-900, Brasil. Bolsista da CAPES.

${ }^{3}$ Departamento de Medicina Veterinária Preventiva (DMVP), UFSM, Santa Maria, RS. *Autor para correspondência: fervogel@smail.ufsm.br

${ }^{4}$ Departamento de Medicina Veterinária Preventiva e Saúde Animal, Faculdade de Medicina Veterinária e Zootecnia, Universidade de São Paulo (USP), Rua Prof. Dr. Orlando Marques Paiva 87, Cidade Universitária. São Paulo, SP 05508-270, Brasil.
}

IgM foi de limitada importância na detecção da infecção via transplacentária em soro fetal bovino.

TERMOS DE INDEXAÇÃO: Neospora caninum, Imunofluorescência indireta, fetos bovinos, Imunoglobulinas G e M (IgG e IgM).

\section{INTRODUÇÃO}

A neosporose é uma doença parasitária causada pelo protozoário intracelular Neospora caninum (Apicomplexa, Sarcocystidae), este parasita foi descrito pela primeira vez em cães na Noruega (Bjerkas et al. 1984). Desde então, relatos da infecção por este agente têm sido feitos em várias espécies, incluindo ruminantes (Dubey \& Lindsay 1996). Em bovinos, a infecção é caracterizada pelo comprometimento reprodutivo em fêmeas, podendo causar abortos do terceiro mês até o final da gestação, porém, mais comumente durante o quinto e o sexto mês de gestação, podendo ocorrer repetidas vezes durante a vida reprodutiva destes animais (Morales et al. 2001a, Garcia-Vazquez et al. 2002).

Achados de anticorpos contra N. caninum em fetos pode determinar a ocorrência da infecção por este protozoário, no entanto, a resposta imunológica depende do estágio de desenvolvimento fetal, do nível de exposição e do tempo en- 
tre a infecção e a coleta de sangue (Dubey 2003). Por outro lado, a presença de anticorpos assegura a ocorrência de infecção transplacentária deste agente sem interferência da imunidade passiva.

Este estudo teve como objetivo investigar a validade da utilização de anticorpos das classes IgM e IgG como marcadores da infecção transplacentária pelo $N$. caninum em fetos bovinos. Além disso, determinar a ocorrência da infecção transplacentária pelo $N$. caninum em amostras de soro fetal de bovinos, coletados em abatedouro do município de Santa Maria, Rio Grande do Sul, Brasil.

\section{MATERIAL E MÉTODOS}

Amostras de sangue de 260 fetos, independente do estágio de gestação, histórico de problema reprodutivo e de vacinação contra Neospora caninum no rebanho, foram coletados em frigorífico na cidade de Santa Maria, no estado do Rio Grande do Sul, Brasil, durante o período de julho de 2007 a março de 2008.

A coleta das amostras foi realizada na linha de abate através de punção da veia jugular ou diretamente do coração. As amostras foram identificadas individualmente, centrifugadas e o soro armazenado em tubos do tipo Eppendorf a $-20^{\circ} \mathrm{C}$.

As amostras de soro foram submetidas à pesquisa de anticorpos anti- $N$. caninum através da técnica de imunofluorescência indireta com taquizoítos da cepa NC-1, conforme metodologia descrita por Dubey et al. (1988) e Paré et al. (1995). As amostras de soro foram diluídas em 1:25 (Wouda et al. 1997a) e testadas para a presença de imunoglobulinas G e M. As amostras positivas, ou seja, com títulos de anticorpos iguais ou superior a 25 não foram tituladas. Como anticorpo secundário, utilizou-se IgG e IgM caprinas anti-bovino conjugadas com fluoresceína ${ }^{5}$, considerou-se positivas as reações que mostraram os taquizoítos com toda sua superfície fluorescente (Conrad et al. 1993, Paré et al. 1995). Em cada lâmina testada, controles negativo e positivo foram utilizados.

\section{RESULTADOS E DISCUSSÃO}

Os resultados obtidos estão apresentados no Quadro 1. Das 260 amostras testadas, em 39 (15\%) foram detectados anticorpos anti-Neospora caninum. Destas amostras, a IgG foi detectada em $97,4 \%$ (38/39) e a IgM foi detectada em $15,4 \%$ (6/39). Em 84,6\% das amostras (33/39), somente imunoglobulinas da classe IgG foram detectadas; $12,8 \%$ das amostras (5/39) continham as duas classes; e em 2,6\% das amostras (1/39) foi detectada somente lgM. Tanto a IgG quanto a IgM em amostras de soro de fetos bovinos podem servir de marcadores da infecção transplacentária por $N$. caninum (Dubey 2003). No presente estudo, a ocorrência de amostras positivas apenas para $\lg$ foi de 14,6\% (38/260); e apenas para IgM foi de 2,3\% (6/260). A frequência de positivos de $15 \%(\operatorname{lgG}+\lg M)$ e de $14,6 \%$, quando considerada apenas a $\lg G$, indica que a pesquisa desta imunoglobulina isoladamente já é suficiente para estudos de prevalência e de ocorrência de infecção transplacentária pelo $N$. caninum. A frequência

\footnotetext{
${ }^{5}$ Clopper Road 910, Gaithersburg, MD 20878, USA.
}

\begin{tabular}{|c|c|c|c|}
\hline & \multicolumn{2}{|c|}{$\operatorname{IgG}$} & \\
\hline & \multicolumn{2}{|c|}{\begin{tabular}{lc}
\multicolumn{2}{c}{$\lg \mathrm{C}$} \\
Positivo(\%) & Negativo (\%)
\end{tabular}} & \\
\hline Positi & $5(1,9)$ & $1(0,4)$ & $6(2,3)$ \\
\hline Negativo(\%) & $33(12,7)$ & $221(85)$ & $254(97,7)$ \\
\hline Total & $38(14,6)$ & $222(85,4)$ & $260(100)$ \\
\hline
\end{tabular}

de detecção de IgM isoladamente nas amostras de soro testadas foi baixa $(0,4 \% ; 1 / 260)$ e aparentemente não é relevante para o diagnóstico em nível populacional. No entanto, a pesquisa conjunta de IgG e IgM poderia contribuir para aumentar a sensibilidade do diagnóstico sorológico de $N$. caninum em fetos. Estudos posteriores devem ser conduzidos na tentativa de estabelecer em que situações é válida a detecção de imunoglobulinas da classe $\mathrm{M}$ e o quanto pode contribuir em estudos de patogenia.

Em alguns estudos de patogenia da infecção pelo $N$. caninum, observou-se que a cinética de detecção de IgM e IgG durante a infecção aguda parece não diferir muito. Serrano et al. (2006) demonstraram que, após a infecção experimental intrauterina de bezerras, anticorpos das classes IgM e IgG foram detectados a partir do dia 15 e 18 pós inoculação (pi), respectivamente. Os níveis máximos de IgG foram detectados no dia 35 pi. Vacas prenhes inoculadas no dia 140 de gestação com taquizoítos apresentaram picos de IgG também no dia 35 pi, mantendo títulos elevados até o final do estudo. Neste estudo não foram pesquisados os níveis de IgM nos animais adultos, porém a presença de IgG e IgM foi analisada nos fetos. Estes começaram a apresentar anticorpos específicos a partir dos 42 dias pi (Bartley et al. 2004). De Marez et al. (1999) compararam os níveis séricos de IgM e IgG em bezerros, demonstrando que em animais infectados experimentalmente com oocistos de $N$. caninum, níveis detectáveis de ambas as imunoglobulinas foram detectados a partir de duas semanas após a infecção. Os níveis de IgM declinaram a partir do dia 30 após a infecção, e os de IgG alcançaram níveis máximos neste período.

No presente estudo, a detecção de anticorpos em 15\% das amostras de soro dos fetos bovinos reafirma a ocorrência de infecção transplacentária por este protozoário independente da via de infecção das matrizes. A transmissão vertical de $N$. caninum em bovinos é suficiente para a manutenção do agente no rebanho, independentemente da presença de hospedeiros definitivos (Paré et al. 1996, Anderson et al. 1997). Os resultados obtidos demonstram que tanto a IgG quanto a IgM podem ser marcadores da infecção transplacentária em fetos de bovinos. No entanto, anticorpos da classe IgG foram detectados com maior frequência do que $\mathrm{lgM}$. Além disso, os resultados indicam que a infecção por este protozoário está disseminada no rebanho bovino, e que, em estudos com amostras fetais, a detecção de IgM anti$N$. caninum parece não contribuir significativamente para os resultados de soroprevalência. 
Quanto à prevalência de 15\% encontrada no presente estudo, resultados semelhantes foram encontrados no Brasil por Guedes et al. (2008) que detectaram uma ocorrência de 12,7\% de amostras positivas para IgG anti-N. caninum em 503 amostras de soro fetal testadas, utilizando a mesma técnica e a mesma diluição do soro. Wouda et al. (1997b) na Holanda examinaram amostras de soro de 2053 fetos e encontraram $17 \%$ de positividade o que corrobora os resultados obtidos no presente estudo. Na Alemanha, (Sondgen et al. 2001) a ocorrência foi de $12,6 \%$ em 135 fetos, e na Argentina, Moore et al. (2002) detectaram ocorrência de 12,1\% em 240 fetos examinados através da técnica de imuno-histoquímica.

Outros estudos demonstram alta prevalência de anticorpos, Morales et al. (2001b), no México encontraram 77\% em 211 fetos examinados; nos Estados Unidos, Anderson et al. (1995), encontraram 42,5\% (266 fetos). No entanto no Brasil Corbellini et al. (2002) demonstraram a presença de antígenos de $N$. caninum, através da técnica de imuno-histoquímica, em 81,8\% dos fetos analisados. Deve-se considerar que estes fetos eram provenientes de propriedades com histórico de problemas reprodutivos e remetidos ao laboratório para diagnóstico, o que poderia justificar essa diferença na prevalência encontrada.

Variações nas taxas de ocorrência de anticorpos detectadas podem ser decorrentes principalmente dos seguintes fatores: tipo de amostragem realizada, da técnica utilizada e da diluição do soro. No entanto, seguramente estes resultados reforçam que a infecção por este protozoário está amplamente disseminada na população estudada. Vários trabalhos no Brasil demonstram a ocorrência da infecção por $N$. caninum em amostras de soro de bovinos tanto de leite como de corte e independente do histórico de problema reprodutivo, com frequências de detecção de anticorpos variando entre 11,2\% (Corbellini et al. 2002), 11,3\% (Vogel et al. 2006) e 53,6\% (Stobbe 1999).

Os resultados obtidos demonstram que a IgG pode ser utilizada como marcador da infecção transplacentária por N. caninum em fetos bovinos. A detecção de IgM parece ser dispensável no diagnóstico de amostras fetais. A importância maior na detecção desta imunoglobulina está relacionada a estudos de patogenia. Paralelamente demonstra que a infecção por este protozoário está disseminada no rebanho bovino.

\section{REFERÊNCIAS}

Anderson M.L., Palmer C.W., Thurmond M.C., Picanso J.P., Blanchard P.C., Breitmeyer R.E., Layton A.W., McAllister M., Daft B., Read D.H., Dubey J.P. \& Conrad P.A. 1995. Evaluation of abortions in cattle attributable to neosporosis in selected dairy herds in California. J. Am. Vet. Med. Assoc. 207:1206-1210.

Anderson M.L., Reynolds J.P., Rowe J.D., Sverlow K.W., Packham A.E., Barr B.C. \& Conrad P.A. 1997. Evidence of vertical transmission of Neospora sp. infection in dairy cattle. J. Am. Vet. Med. Assoc. 210:1169-1172.

Bartley P.M., Kirvar E., Wright S., Swales C., Esteban I., Buxton D., Maley S.W., Schock A., Rae A.G., Hamilton C. \& Innes E.A. 2004. Maternal and fetal immune responses of cattle inoculated with Neospora caninum at mid-gestation. J. Comp. Pathol. 130:81-91.

Bjerkas I., Mohn S.F. \& Presthus J. 1984. Unidentified cyst-forming sporozoan causing encephalomyelitis and myositis in dogs. Zeitschrift für Parasitenkunde 70:271-274.
Conrad P.A., Sverlow K., Anderson M., Rowe J., Bondurant R., Tuter G., Breitmeyer R., Palmer C., Thurmond M., Ardans A., Dubey J.P., Duhamel G. \& Barr B. 1993. Detection of serum antibody responses in cattle with natural or experimental Neospora infections. J. Vet. Diagn. Invest. 5:572-578.

Corbellini L.G., Driemeier D., Cruz C.F.E., Gondim L.F.P. \& Wald V. 2002. Neosporosis as a cause of abortion in dairy cattle in Rio Grande do Sul, southern Brazil. Vet. Parasitol. 103(3):195-202.

De Marez T., Liddell S., Dubey J.P., Jenkins M.C. \& Gasbarre L. 1999. Oral infection of calves with Neospora caninum oocysts from dogs: humoral and cellular immune responses. Int. J. Parasitol. 29:1647-1657.

Dubey J.P. 2003. Review of Neospora caninum and neosporosis in animals. Korean J. Parasitol. 41:1-16.

Dubey J.P., Hattel A.L., Lindsay D.S. \& Topper M.J. 1988. Neonatal Neospora caninum infection in dogs: isolation of the causative agent and experimental transmission of Neospora caninum. J. Am. Vet. Assoc. 193:1259-1263.

Dubey J.P. \& Lindsay D.S. 1996. A review of Neospora caninum and neosporosis. Vet. Parasitol. 67:1-59.

Garcia-Vazquez Z., Cruz-Vazquez C., Medina E.L., Garcia T.D. \& Chavarria M.B. 2002. Serological survey of Neospora caninum infection in dairy cattle herds in Aguascalientes, Mexico. Vet. Parasitol. 106:115-120.

Guedes M.N.P., Guimarães A.M., Rocha M.B.M. \& Hirsch C. 2008. Frequencia de anticorpos anti-Neospora caninum em vacas e fetos provenientes de municípios do Sul de Minas Gerais. Revta Bras. Parasitol. Vet. 17:189-194.

Moore D.P., Campero C.M., Odeón A.C., Posso M.A., Cano D., Luenda M.R., Basso W., Venturini M.C. \& Spath E. 2002. Seroepidemiology of beef and dairy herds and fetal study of Neospora caninum in Argentina. Vet. Parasitol. 107:303-316.

Morales E., Trigo F.J., Ibarra F., Puente E. \& Santacruz M. 2001a. Neosporosis in Mexican dairy herds: Lesions and immunohistochemical detection of Neospora caninum in fetuses. J. Comp. Pathol. 125:58-63.

Morales E., Trigo F.J., Ibarra F., Puente E. \& Santacruz M. 2001b. Seroprevalence study of bovine Neosporosis in Mexico. J. Vet. Diagn. Invest. 13:413-415.

Paré J., Hietala S.K. \& Thurmond M.C. 1995. Interpretation of an indirect fluorescent antibody test for diagnosis of Neospora sp. infection in cattle. J. Vet. Diagn. Invest. 7(2):273-275.

Paré J., Thurmond M.C. \& Hietala S.K. 1996. Congenital Neospora caninum infection in dairy cattle and associated calfhood mortality. Can. J. Vet. Res. 60:133-139.

Serrano E., Ferre I., Osoro K., Aduriz G., Mateos-Sanz A., Martinez A., Atxaerandio R., Hidalgo C.O. \& Ortega-Mora L.M. 2006. Intrauterine Neospora caninum inoculation of heifers. Vet. Parasitol. 135:197-203.

Sondgen P., Peters M., Bärwald A., Wurm R., Holling F., Conraths F.J. \& Schares G. 2001. Bovine neosporosis: immunoblot improves foetal serology. Vet. Parasitol. 102(4):279-290.

Stobe N.S. 1999. Estudo interarivo entre a presença de anticorpos antiNeospora caninum e a ocorrência de abortamentos em bovinos no noroeste do Estado de São Paulo. Tese de Doutorado em parasitologia, Faculdade de Medicina Veterinária e Zootecnia, USP, São Paulo. 44p.

Vogel F.S.F, Arenhart S. \& Bauermann F.V. 2006. Anticorpos antiNeospora caninum em bovinos, ovinos e bubalinos no Estado do Rio Grande do Sul. Ciência Rural 36 (6):2010-01.

Wouda W., Dubey J.P. \& Jenkins M.C. 1997a. Serological diagnosis of bovine fetal neosporosis. J. Parasitol. 83:545-547.

Wouda W., Moen A.R., Visser I.J.R. \& Van Knapen F. 1997b. Bovine fetal neosporosis: A comparision of epizootic and sporadic abortion cases and diferent age classes with regard to lesion severity and immunohistochemical identification of organisms in brain, heart and liver. J. Vet. Diagn. Invest. 9:180-185. 